Proceedings

\title{
Microcentrifuge Tubes as Disposable Immunoelectrochemical Cells for the On-Site Determination of GFAP, Biomarker of Hemorrhagic Stroke ${ }^{+}$
}

\author{
Andrea González-López ${ }^{1}$, Estefanía Costa-Rama 1,* , Carmen García-Cabo Fernández 2, \\ Lorena Benavente Fernández 2, Sergio Calleja-Puerta 2, Beatriz Fernández-García ${ }^{\text {, }}$ \\ Rosario Pereiro ${ }^{1}$ and M. Teresa Fernández-Abedul ${ }^{1}$ \\ 1 Department of Physical and Analytical Chemistry, University of Oviedo, Av. Julián Clavería 8, 33006 \\ Oviedo, Spain; agl.andreaglez@gmail.com (A.G.-L.); costaestefania@uniovi.es (E.C.-R.); \\ fernandezbeatriz@uniovi.es (B.F.-G.); mrpereiro@uniovi.es (R.P.); mtfernandeza@uniovi.es (M.T.F.-A.) \\ 2 Department of Neurology, Central University Hospital of Asturias (HUCA), Av. Roma s/n, 33011 Oviedo, \\ Spain; c.garciacabo@gmail.com (C.G.-C.F.); lbfbenfer@gmail.com (L.B.F.); scallejap@gmail.com (S.C.-P.) \\ * Correspondence: costaestefania@uniovi.es \\ + Presented at the 1st International Electronic Conference on Biosensors, 2-17 November 2020; Available \\ online: https://iecb2020.sciforum.net/.
}

Received: date; Accepted: date; Published: date

\begin{abstract}
Stroke is the leading cause of mortality worldwide. Differentiating patients with intracerebral hemorrhage (ICH) or ischemic stroke in the first hours of symptoms onset is of paramount importance to the optimal management of patients. Current diagnosis of acute stroke relies on neuroimaging techniques that provide valuable information but not always are readily available. In this context, the development of analytical tools capable of a rapid and on-site differentiation between the types of stroke is an important challenge with great socio-economic benefits. Glial fibrillary acidic protein (GFAP) is considered one of the intracerebral hemorrhage (ICH) biomarkers in patients with symptoms of acute stroke. In this work, a simple electroanalytical device for the analysis of GFAP was developed combining stainless steel pins and a microcentrifuge tube. The sandwich immunoassay for the determination of GFAP was carried out inside the microcentrifuge tube immobilizing the capture antibody on the bottom of the tube. The three stainless-steel pins acting as electrodes were inserted in the cap in such a way that, when the immunoassay is finished, the tube is turned bottom up allowing the electrochemical detection in the same tube.
\end{abstract}

Keywords: immunosensor; electrochemical sensor; electroanalytical device; microcentrifuge-tube electrochemical cell; stainless-steel pins; stroke; biomarker; GFAP

\section{Introduction}

Acute stroke is a cerebrovascular disease that occurs when a blood vessel of the brain is broken (hemorrhagic stroke) or plugged by a blood clot (ischemic stroke). Because of this breakage or block, part of the brain is deprived of the oxygen and glucose necessary for its proper function, leading to the cell death after some minutes. The survival rate and the quality of life of survivors heavily depends on the time it takes to apply the suitable treatment; however, this is not easy since hemorrhagic (HS) and ischemic stroke (IS) have a different pathophysiology and, derived from this, a different treatment. While there is a treatment for IS that reverses the most devastating effects of the disease, this does not happen with HS, and treatment for IS could even worsen HS. In addition, 
the result of treatment in the case of IS is time dependent [1]. Because of this, differential diagnosis between IS and HS in the acute stage is one of the major challenges of neurovascular research.

Current diagnostic evaluation of acute stroke heavily relies on neuroimaging techniques such as brain computed tomography (CT) and magnetic resonance imaging (MRI). While neuroimaging provides valuable diagnostic information, it is not always readily available and sometimes is not possible to perform it on time. On this basis, the decrease of the time since the first symptoms appear and the treatment is applied will lead to greater chances of full recovery of stroke patients. For all this, the development of simple and portable devices for the determination of biomarkers able to differentiate between HS and IS in the acute stage is of enormous importance since they would allow the rapid and decentralized differential diagnosis in e.g., remote areas, equipped ambulances or primary care centers.

Glial fibrillary acidic protein (GFAP) is considered one of the intracerebral hemorrhage (ICH) biomarker in patients with symptoms of acute stroke. It has been showed that GFAP levels in blood serum of patients with HS are higher than those in patients with IS [2]. Therefore, the development of analytical devices for the determination of this protein is promising since it will allow a rapid differential diagnosis of stroke.

As it is known, point-of-care tests (POCTs) offer great advantages for on-site diagnosis. They are characterized by the use of small-size equipment and simple procedures, undoubtedly leading to decentralized analysis where total analysis time is also considerably reduced [3]. In the last years, the interest in developing analytical devices using low-cost and mass-produced materials is continuously growing [4-7].

In this work, a sandwich immunoassay developed for the determination of GFAP using HRP as label and $3,3^{\prime}, 5,5^{\prime}$ tetramethylbenzidine (TMB) as enzymatic substrate was adapted for microcentrifuge tubes. Then, the whole immunoassay is carried out inside a tube immobilizing the capture antibody on the bottom of the tube. Three stainless-steel pins (one of them modified with carbon ink) are inserted in the cap of the tube. Those pins act as working (modified with carbon ink), reference and counter electrodes. This type of electrodes, based on conductive mass-produced elements of common use, have already been probed as convenient electrodes in some other devices $[4,5,8,9]$. With the pin-based electrodes inserted in the tube cap, when the immunoassay is finished, the immunoelectrochemical device is turned bottom up allowing electrochemical detection in the same tube. Furthermore, microcentrifuge tubes are also a common and very cheap and massproduced lab material. They are a promising alternative to common ELISA microplates as platform for immunoassays where electrochemical detection can be easily integrated.

\section{Materials and Methods}

\subsection{Chemicals, Materials and Apparatus}

GFAP matched antibody pair kit was purchased from Abcam and includes a capture antibody (Ab1) and a biotinylated detection antibody (Bio-Ab2) as well as a calibration protein standard. Additional buffers required for the assay were prepared as indicated by the supplier: 10xPBS $(0.14 \mathrm{M}$ $\mathrm{NaCl}, 0.003 \mathrm{M} \mathrm{KCl}, 0.002 \mathrm{M} \mathrm{KH}_{2} \mathrm{PO}_{4}$ and $0.01 \mathrm{M} \mathrm{Na}_{2} \mathrm{HPO}_{4}$, $\mathrm{pH} 7.2$ ); coating buffer (35 mM NaHCO , $15 \mathrm{mM} \mathrm{Na} 2 \mathrm{CO}_{3}$, pH 9.6); washing buffer (0.05\% Tween ${ }^{\circledR 20}$ in 1 XPBS); blocking buffer (1\% BSA and $0.05 \%$ Tween ${ }^{\circledR 2} 2$ in $\left.1 \mathrm{XPBS}\right)$; stop solution $\left(0.1 \mathrm{M} \mathrm{H}_{2} \mathrm{SO}_{4}\right)$. Ultrapure water obtained from a Millipore Direct-Q ${ }^{\text {TM }} 5$ purification system was used throughout this work.

N,N-Dimethylformamide (DMF), supplied by from VWR International., and carbon paste (C10903P14), provided by Gwent Electronic Materials Ltd., were used for preparing the carbon ink.

The 500- $\mu \mathrm{L}$ microcentrifuge tubes, in which the immunoassay was performed, were purchased from Labbox Labware and the stainless-steel pins $(26 \times 0.59 \mathrm{~mm})$ from Metalurgia Folch.

A 3-pin Dupont female cable was used as interface between the pins and the potentiostat ( $\mu$ AUTOLAB TYPE III potentiostat (Methrom) controlled by the NOVA software version 2.1).

\subsection{Electrochemical Cell Design}


Three stainless-steel pins were inserted on the cap of a 500- $\mu \mathrm{L}$ microcentrifuge tube (Figure 1A). These pins acted as electrodes: two were used unmodified (the ones acting as reference (RE) and counter (CE) electrodes); the third (which acts as working electrode (WE)) was modified with carbon ink. This was prepared by diluting carbon paste with DMF $(50 \% w / w)$ and sonicating it $(37 \mathrm{kHz}$ of frequency and $320 \mathrm{~W}$ of power) for $1 \mathrm{~h}$. Then, the pins were mass modified by painting their heads thrice with the carbon ink using a brush. Between the two first coatings, the pins were introduced in the oven at $70{ }^{\circ} \mathrm{C}$ for $15 \mathrm{~min}$. After the last one, they were left for $1 \mathrm{~h}$ at $70^{\circ} \mathrm{C}$.
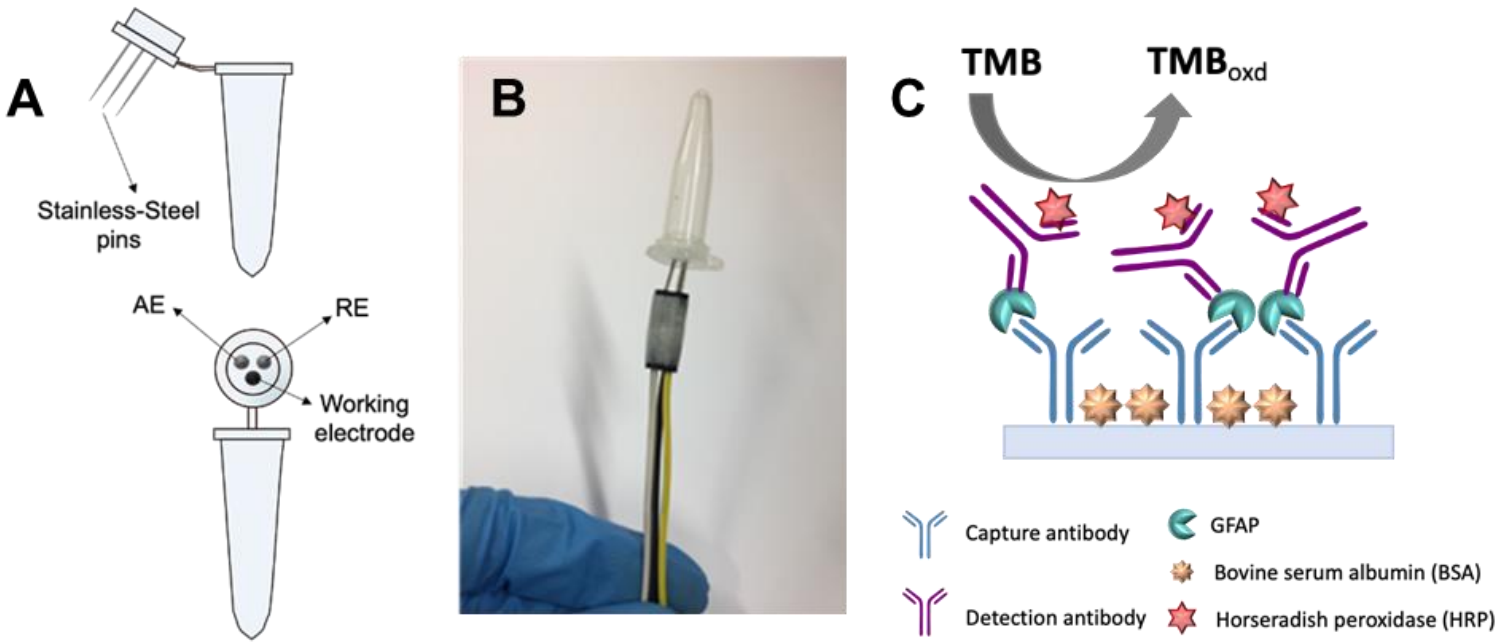

Figure 1. (A) Schematic representation of the electrochemical cell fabricated using a 1-500 $\mu \mathrm{L}$ microcentrifuge tube and three stainless-steel pins (one modified with carbon ink (acting as WE) and two bare ones (acting as RE and CE); (B) Picture of the tube-based electrochemical cell with the pins inserted in the three-pin Dupont connector; (C) Schematic representation of the immunoassay for GFAP, performed inside the microcentrifuge tube.

\subsection{Immunoassay Procedure}

First of all, the inner walls of the microcentrifuge tube were modified with the Ab1 incubating $50 \mu \mathrm{L}$ of Ab1 solution during $2 \mathrm{~h}$ on a plate shaker at $400 \mathrm{rpm}$. Then, the microcentrifuge tube was washed three times with $350 \mu \mathrm{L}$ of the washing buffer. This washing step was repeated after each incubation. Afterwards, a blocking step was carried out incubating $300 \mu \mathrm{L}$ of the blocking buffer for $2 \mathrm{~h}$ at $400 \mathrm{rpm}$. After another washing step, the tube was ready for incubation with the GFAP. Thus, $50 \mu \mathrm{L}$ of GFAP dilution (prepared in 1xPBS) were incubated for $2 \mathrm{~h}$ at $400 \mathrm{rpm}$. Then, $50 \mu \mathrm{L}$ of Bio$\mathrm{Ab} 2$ solution prepared in the blocking buffer were incubated during $1 \mathrm{~h}$ at $400 \mathrm{rpm}$. After that, $50 \mu \mathrm{L}$ of a 1:2 diluted HRP-streptavidin solution provided with the kit was added and incubated during 1 $\mathrm{h}$ at $400 \mathrm{rpm}$. Then, $100 \mu \mathrm{L}$ of TMB solution were incubated for $15 \mathrm{~min}$ in the dark at $400 \mathrm{rpm}$. Finally, $100 \mu \mathrm{L}$ of the stop solution were added to finish the enzymatic reaction. A scheme of the complete immunoassay is represented in Figure 1C. Once the immunoassay was finished, the closed microcentrifuge tube was inverted and the tip of the pins inserted into the three-pin Dupont female connector for electrochemical measurement.

\subsection{Electrochemical Measurements}

For recording the electrochemical measurements, the tube-based cell was turned upside down and the three stainless-steel pins were connected to the potentiostat through a three-pin Dupont female connectors (Figure 1B). For the study of the electrochemical behavior of TMB in the tube-based cell, cyclic voltammograms (CVs) were recorded from -0.2 to $+0.4 \mathrm{~V}$ at a scan rate of $0.1 \mathrm{~V} \cdot \mathrm{s}^{-1}$.

For obtaining the analytical signal once the immunoassay was finished, a chronoamperogram was recorded applying $-0.1 \mathrm{~V}$ for $25 \mathrm{~s}$. The analytical signal was the current measured at this time. 


\section{Results and Discussion}

\subsection{Evaluation of the Tube-Based Electrochemical Cell}

In order to evaluate the capability of this new electrochemical cell, the electrochemical behavior of TMB (the enzymatic substrate used for the detection of the immunoassay) was studied by cyclic voltammetry. The scan recorded between -0.1 and $+0.4 \mathrm{~V}$ (Figure 2 ) shows an anodic $\left(\mathrm{E}_{\mathrm{pa}}=+0.071 \mathrm{~V}\right)$ and a cathodic $\left(E_{p c}=+0.024 \mathrm{~V}\right)$ peaks with peak current intensities of $21.87 \mu \mathrm{A}$ and $-16.24 \mu \mathrm{A}$, respectively. In order to study the reproducibility of this platform, CVs of TMB were recorded using five different electrochemical cells obtaining a relative standard deviation (RSD), for the peak current intensities, lower than $6 \%$.

Since the analytical signal that will be obtained after performing the immunoassay is due to the reduction of the TMB previously oxidized by the HRP, in view of Figure 2, a potential of $-0.1 \mathrm{~V}$ was chosen for recording the chronoamperograms, in order to guarantee the reduction of TMB.

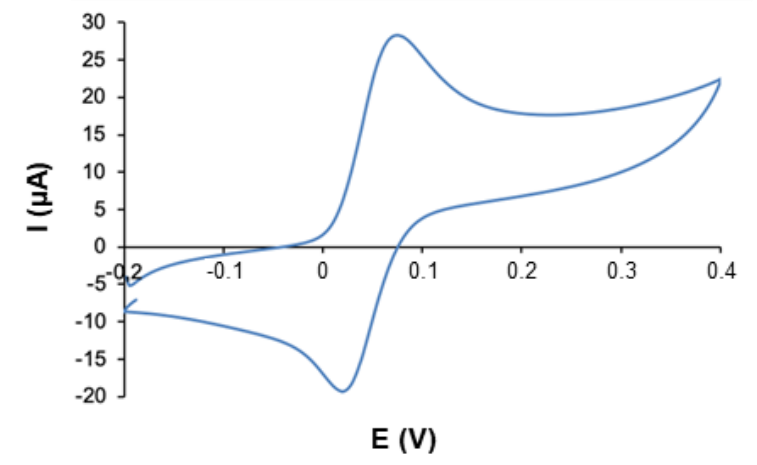

Figure 2. Cyclic voltammogram recorded of $\mathrm{TMB}$ in $0.1 \mathrm{M} \mathrm{H}_{2} \mathrm{SO}_{4}$ (at a scan rate of $0.1 \mathrm{~V} \cdot \mathrm{s}^{-1}$ ) using the developed tube-based electrochemical cell.

\subsection{Analytical Signals of the Immunoassay}

With the aim of testing if this new device was adequate for performing the immunoassay and the detection, a study with two concentrations of GFAP standard $\left(0.1\right.$ and $\left.1 \mathrm{ng} \cdot \mathrm{mL}^{-1}\right)$ was carried out. As can be seen in Figure 3A, clear differences in the color were obtained for solutions of the blank and those with two GFAP concentrations. Chronoamperograms recorded (Figure 3B) show significant differences in the analytical signal obtained for the blank and each one of the concentrations. These results show the great potential of this new platform for performing bioassays with electrochemical detection.

\section{A}

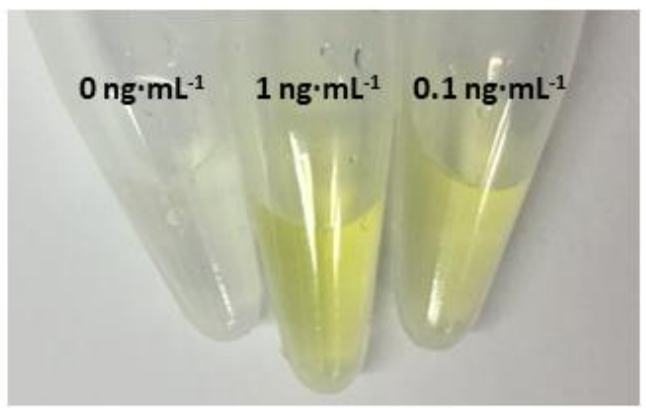

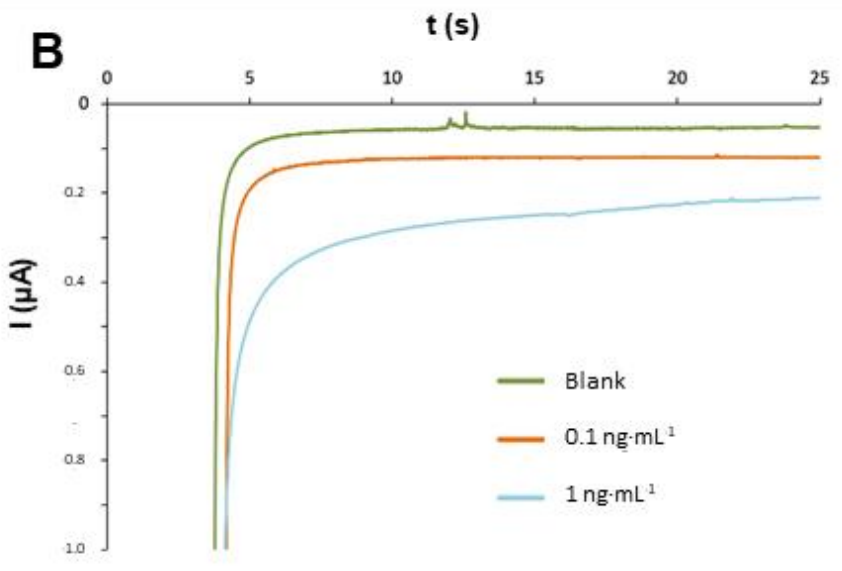


Figure 3. (A) Photograph of $500-\mu \mathrm{L}$ microcentrifuge tubes after performing the immunoassay for 1 $\mathrm{ng} \cdot \mathrm{mL}^{-1}$ and $0.1 \mathrm{ng} \cdot \mathrm{mL}^{-1}$ inside them (a blank is also included); (B) Chronoamperograms recorded (at $-0.1 \mathrm{~V}$ for $25 \mathrm{~s}$ ) in the tube-based cell once the immunoassay performed inside was finished.

\section{Conclusions}

A new integrated platform for electroanalysis was developed using low-cost and common materials such as microcentrifuge tubes and stainless steel pins. This device allows to perform a bioassay inside the tube and then, turning the tube upside down, the electrochemical measurement is performed. The good precision of this tube-based electrochemical cell makes possible to obtain a simple, cheap and disposable point-of-need device. In this case, we have used the developed device for performing an immunoassay for GFAP detection, but its simplicity, good reproducibility and versatility suggest this device can be a promising approach for many applications in which on-site analysis are required.

Acknowledgments: This work has been funded by the Spanish Ministry of Science and Innovation under the Project PID2019-107838RB-100. Andrea González-López thanks the Consejería de Educación y Cultura del Gobierno del Principado de Asturias for the award of her "Severo Ochoa" grant (BP17-36).

\section{References}

1. García-Cabo, C.; Llano-Suárez, P.; Benavente-Fernández, L.; Calleja-Puerta, S.; Costa-Fernández, J.M.; Fernández-Abedul, M.T. Obtaining information from the brain in a non-invasive way: Determination of iron in nasal exudate to differentiate hemorrhagic and ischemic strokes. Clin. Chem. Lab. Med. 2020, 58, 847853, doi:10.1515/cclm-2019-0899.

2. Foerch, C.; Niessner, M.; Back, T.; Bauerle, M.; De Marchis, G.M.; Ferbert, A.; Grehl, H.; Hamann, G.F.; Jacobs, A.; Kastrup, A.; et al. Diagnostic accuracy of plasma glial fibrillary acidic protein for differentiating intracerebral hemorrhage and cerebral ischemia in patients with symptoms of acute stroke. Clin. Chem. 2012, 58, 237-245, doi:10.1373/clinchem.2011.172676.

3. Luppa, P.B.; Müller, C.; Schlichtiger, A.; Schlebusch, H. Point-of-care testing (POCT): Current techniques and future perspectives. TrAC - Trends Anal. Chem. 2011, 30, 887-898, doi:10.1016/j.trac.2011.01.019.

4. Rama, E.C.; Costa-García, A.; Fernández-Abedul, M.T. Pin-based electrochemical glucose sensor with multiplexing possibilities. Biosens. Bioelectron. 2017, 88, 34-40, doi:10.1016/j.bios.2016.06.068.

5. García-Miranda Ferrari, A.; Amor-Gutiérrez, O.; Costa-Rama, E.; Fernández-Abedul, M.T. Batch injection electroanalysis with stainless-steel pins as electrodes in single and multiplexed configurations. Sens. Actuators B Chem. 2017, 253, 1207-1213, doi:10.1016/j.snb.2017.07.148.

6. Berg, K.E.; Adkins, J.A.; Boyle, S.E.; Henry, C.S. Manganese Detection Using Stencil-printed Carbon Ink Electrodes on Transparency Film. Electroanalysis 2016, 28, 679-684, doi:10.1002/elan.201500474.

7. Glavan, A.C.; Ainla, A.; Hamedi, M.M.; Fernández-Abedul, M.T.; Whitesides, G.M. Electroanalytical devices with pins and thread. Lab. Chip. 2016, 16, 112-119, doi:10.1039/C5LC00867K.

8. Nanni, P.I.; González-López, A.; Nunez-Bajo, E.; Madrid, R.E.; Fernández-Abedul, M.T. Staple-Based Paper Electrochemical Platform for Celiac Disease Diagnosis. ChemElectroChem 2018, 5, 4036-4045, doi:10.1002/celc.201800743.

9. González-López, A.; Blanco-López, M.C.; Fernández-Abedul, M.T. Micropipette Tip-Based Immunoassay with Electrochemical Detection of Antitissue Transglutaminase to Diagnose Celiac Disease Using Staples and a Paper-Based Platform. ACS Sens. 2019, 4, 2679-2687, doi:10.1021/acssensors.9b01096.

Publisher's Note: MDPI stays neutral with regard to jurisdictional claims in published maps and institutional affiliations.

(C) 2020 by the authors. Submitted for possible open access publication under the terms and conditions of the Creative Commons Attribution (CC BY) license (http://creativecommons.org/licenses/by/4.0/). 